2019-06

\title{
Do alternative reproductive strategies in the Wellington tree weta represent different behavioural types?
}

Wilson, Alexander

http://hdl.handle.net/10026.1/14450

10.1111/eth.12862

Ethology

Wiley

All content in PEARL is protected by copyright law. Author manuscripts are made available in accordance with publisher policies. Please cite only the published version using the details provided on the item record or document. In the absence of an open licence (e.g. Creative Commons), permissions for further reuse of content should be sought from the publisher or author. 


\title{
Do alternative reproductive strategies in the Wellington tree weta represent different behavioural types?
}

\author{
Alexander D. M. Wilson ${ }^{1,2}$ (D) | Clint D. Kelly ${ }^{3}$ (D)
}

${ }^{1}$ School of Biological \& Marine Sciences, Marine Biology and Ecology Research Centre, University of Plymouth, Devon, UK

${ }^{2}$ School of Life and Environmental Sciences, Centre for Integrative

Ecology, Deakin University, Waurn Ponds, Victoria, Australia

${ }^{3}$ Département des Sciences

Biologiques, Université du Québec à

Montréal, Montréal, Quebec, Canada

\section{Correspondence}

Alexander D. M. Wilson, School of Biological \& Marine Sciences, Marine Biology and Ecology Research Centre, University of Plymouth, Devon, UK.

Email: alexander.wilson@ymail.com

\section{Funding information}

This work was supported by the Canada Research Chairs Program (C.D.K.). A.D.M.W. was supported in part by an Alfred Deakin Research Fellowship.

Editor: T. Tregenza

\begin{abstract}
In many animal species, variation in reproductive success among individuals has led to the evolution of alternative mating strategies, which in the case of insects can often be correlated with developmental trajectories. In the Wellington tree weta, Hemideina crassidens, males can mature at the 8th, 9th or 10th instar, while females mature at the 10th instar only. A number of morphological attributes including male head and mandible size correlate with final instar number, and as these attributes represent a form of weaponry, they are often used in mate/site guarding and malemale competition. Tenth instar males have larger head/mandible/body sizes and show a conventional (guarder) reproductive strategy, whereas smaller 8th instar males typically show an unconventional (sneaker) strategy. In contrast, 9th instar males are predicted to adopt a "jack-of-all-trades" strategy whereby they can fight or sneak depending context. Here, we tested whether alternative reproductive morphs exhibit strategy-specific differences in risk-taking associated with refuge emergence, activity and antipredator behaviour and further, whether these traits correlate to form a behavioural syndrome. We found that tree weta show consistent and repeatable differences in activity and refuge use at the individual level; however, behavioural covariances suggest that only 8th instar males exhibit a behavioural syndrome. That 9th instar males show high plasticity and variance in their gallery-related behaviours supports the hypothesis that these males are a "jack-of-all-trades." Contrary to our predictions, antipredator behaviour was not correlated with other traits, and differences in behaviour overall were consistently more pronounced between individuals rather than between male morphs or sexes.
\end{abstract}

\section{KEYWORDS}

alternative reproductive strategies, behavioural syndromes, personality, sexual selection, weta

\section{1 | INTRODUCTION}

Intense sexual selection drives the evolution of alternative mating strategies through the simple but powerful process of creating variance in reproductive success among males (Shuster \& Wade, 2003). Variation in reproductive success arises whenever a male gains a mating or fertilization at the expense of another male; thus, sexual selection intensifies as fewer males acquire a larger share of the available reproductive opportunities. As sexual selection on conventional males (i.e., guarder, bourgeois, dominant or major males), who tend to aggressively defend groups of receptive females or breeding resources, becomes stronger, a "mating niche" develops in which other unconventional males (i.e., sneaker, satellite, subordinate or minor males) can invade and attempt to steal 
mating opportunities using alternative reproductive behaviours (Oliveira, Taborsky, \& Brockmann, 2008; Shuster, 2008; Shuster \& Wade, 2003).

The broad and general categories of "guarder" and "sneaker," however, comprise several traits that act in concert to achieve mating success in a specialized and particular fashion across taxa (Brockmann, Oliveira, \& Taborsky, 2008). For example, guarder males are typically larger, more aggressive, territorial and less risk averse than "sneaker" males who are typically smaller, more timid in terms of engaging in agonistic encounters and actively attempt to steal mating opportunities through subterfuge, including behaving similarly to, and in some cases, mimicking the physical appearance of females to cuckold guard males (e.g., Gross, 1982; Hanlon, Naud, Shaw, \& Havenhand, 2005; Kodric-Brown, 1986; Küpper et al., 2016). While these intra-sexual differences in reproductive tactics have been studied for some time in terms of ecology and evolution (see Taborsky \& Brockmann, 2010; Taborsky, Oliveira, \& Brockmann, 2008), it is surprising that, as yet, comparatively little effort has been made to consider these differences in the context of animal personality [consistency in behaviour over time and across situations (Réale, Reader, Sol, McDougall, \& Dingemanse, 2007)], particularly when inter-sexual differences in personality traits are common (Schuett, Tregenza, \& Dall, 2010). Moreover, if alternative morphotypes consistently exhibit particular behaviours as part of a suite of strategy-specific traits acting in concert to improve or accrue mating success, then we would expect morphspecific behavioural types or syndromes to evolve (Brockmann, 2008; Sih, Bell, Johnson, \& Ziemba, 2004). Behavioural types represent a manner by which to categorize individuals according to their behaviour along a given axis of personality (e.g., more or less bold), and by definition, behavioural syndromes are suites of correlated behaviours across multiple observations either within a given axis (boldness) or more holistically across axes (boldness, activity, exploration, aggression or sociability) (Sih et al., 2004). Though behavioural syndromes have been documented in a wide range of animals (Binder et al., 2016; Bókony, Kulcsár, Tóth, \& Liker, 2012; Carter, Goldizen, \& Tromp, 2010; Dingemanse et al., 2007; Wilson \& Krause, 2012; Wilson et al., 2010, 2017), comparisons of syndromes between the sexes are sparse (but see Chapman, Hegg, \& Ljungberg, 2013; Michelangeli, Chapple, \& Wong, 2016), and to our knowledge, neither behavioural types nor syndromes have as yet been quantified within intra-sexual alternative mating strategies.

In this study, we use the Wellington tree weta, Hemideina crassidens (Orthoptera: Tettigonioidea: Anostostomatidae Blanchard, 1851), to test the hypothesis that alternative reproductive morphs exhibit strategy-specific personality traits (as behavioural types) and that these traits correlate to form a behavioural syndrome (in the context of risk-taking associated with refuge use, site vigilance and antipredator behaviour). The Wellington tree weta is a large, flightless and nocturnal insect endemic to New Zealand (Gibbs, 1998, 2001). Hemideina crassidens seeks protection from predators by refuging in tree cavities (hereafter galleries). Galleries can be limiting in nature, thus several females will refuge in a given gallery at the same time. This increases the environmental potential for polygyny and causes males to fight for control of larger galleries. Males sporting larger mandibular weaponry tend to control access to galleries housing more females. This intense sexual selection has led to the evolution of irreversible alternative mating strategies: males mature at either the 8th, 9th or 10th instar (females mature at the 10th instar only) with weapon size positively correlating with instar number (Kelly \& Adams, 2010; Spencer, 1995). Field and laboratory observations suggest that smaller males adopt a wandering or sneaking strategy to obtain matings either opportunistically within a gallery guarded by larger males, with females in the vegetation away from a gallery or by gaining access to galleries that have entrance holes that are too small for large males (Kelly, 2006b). Larger males appear to accrue matings by controlling larger harems (Kelly, 2005a, 2006c, 2008a), likely by having superior resource-holding potential (RHP) relative to rivals (Kelly, 2006a), and as such, are rarely observed mating away from a gallery.

Here, we investigated inter- and intra-sexual differences in three gallery-related behaviours and two antipredator behaviours. We predicted that smaller, 8th instar males would emerge earlier, would more frequently check their gallery status (entry/exit) and show reduced antipredator/aggressive behaviour than larger 9th and 10th instar males. This conforms to previous observations (Kelly, 2006a,2006c; Spencer, 1995) of small males furtively searching for females that are outside galleries or occupying unguarded galleries and evidence that larger males show more sedentary guarding behaviour around their gallery. Because 10th instar males guard galleries and/or wait for females to arrive at galleries, we predicted that they would emerge later, spend less time outside the gallery and, due to increased gallery vigilance, show fewer gallery exits overall to reduce the risk of gallery take-over by rival males (if residency plays a role in maintaining ownership of a gallery) or attack by predators (if larger, slow-moving males experience greater predation risks). Similarly, 10th instar males might incur greater predation risks and are generally more aggressive than other morphs (Kelly, 2006a,2006b,2006c,2006d). We predicted that they would exhibit more intense antipredator responses. We also predicted that 9th instar males, which are assumed to adopt a jack-of-all-trades strategy, would show intermediate and more plastic responses such that they would behave like 8 th instar males in some situations (i.e., higher activity associated with mate searching) and like 10th instar males in other situations (i.e., increased antipredator response compared to 8th instar males). We also explored the gallery-related and antipredator behaviours of females and compared them to males. Assuming that female behaviour represents the naturally selected optimum (see Lande, 1980), any sex difference can be attributed to sexual selection. In addition to examining the inter- and intra-sexual differences in ecologically relevant behaviours, we also examine the repeatability of three gallery-related behaviours and whether the behaviours are correlated within and between the sexes. 

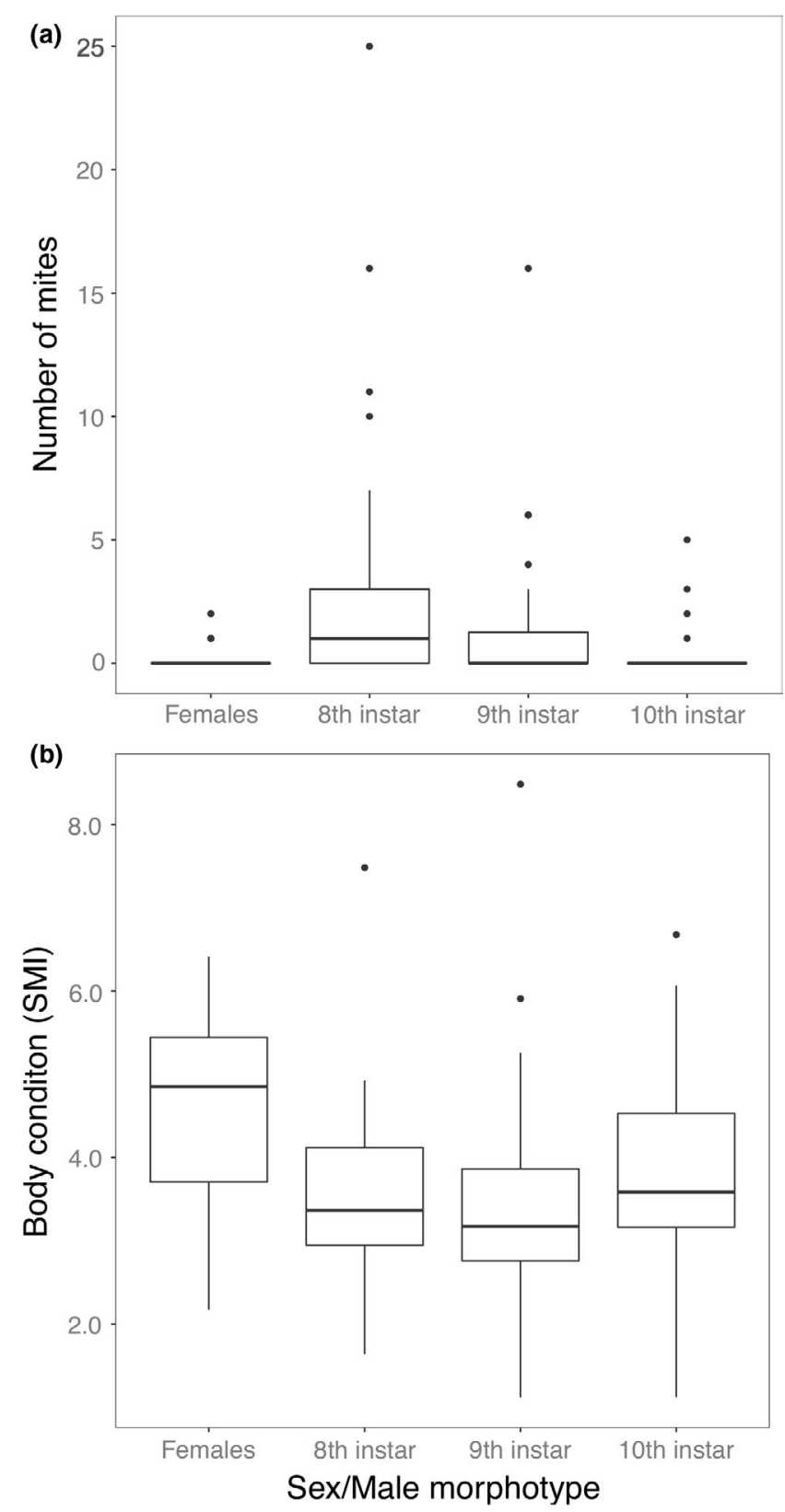

FIGURE 1 Boxplots showing that (a) male Hemideina crassidens had significantly more ectoparasitic mites (Nothotrombicula deinacridae) than females (b) and females were in significantly better body condition (scaled mass index, SMI) than males. Statistical analyses tested differences between the sexes (i.e., all male morphs pooled) but male data are shown here for each morph. The box represents the lower (25\%) and upper (75\%) quartiles, the solid dark horizontal line is the median and the whiskers indicate 1.5 times the size of the hinge, that is the $75 \%$ minus $25 \%$ quartiles. Samples sizes are $N=32$ for females and each male morph

\section{2 | METHODS}

Our study was conducted on Te Pakeka/Maud Island, New Zealand $\left(41^{\circ} 02^{\prime} \mathrm{S}, 173^{\circ} 540^{\prime} \mathrm{E}\right)$ during Mar-Apr, 2016. Maud Island is a 309-ha scientific reserve free of alien mammalian predators (e.g., Mus and Rattus spp.); the primary endemic predator of weta on the island is the morepork owl, Ninox novaeseelandiae. We collected approximately 10 adult tree weta every 72 hr over 13 separate sampling periods. Weta were collected from foliage along the same $2 \mathrm{~km}$ walking track between 1,900 and 2,100 hr, and within each sampling period; individuals from both sexes and each male morph were collected (although the ratios changed such that equal sample sizes were obtained overall.) Only individuals that were found to be complete and lacking physical damage (broken or missing limbs) were included in the study. We collected a total of $N=32$ of each male morph (8th instar: $2.7 \pm 0.5 \mathrm{~g}$ (body mass), $16.5 \pm 1.6 \mathrm{~mm}$ (head length); 9th instar: $4.0 \pm 0.7 \mathrm{~g}, 21.4 \pm 1.6 \mathrm{~mm}$; 10th instar: $5.6 \pm 0.5 \mathrm{~g}, 26.5 \pm 1.3 \mathrm{~mm}$ ) and $N=32$ females $(4.8 \pm 0.9 \mathrm{~g})$.

Following field collection, tree weta were brought back to the laboratory on Maud Island and immediately placed in individual 9.6-L plastic buckets (with perforated lids) containing ad libitum food (pieces of fresh apple) and a wooden artificial refuge (45 × 45 $\times 220$ mm, 19 mm opening; see Figure 1 in Kelly, 2008b). The refuges resembled the size and shape of naturally occurring galleries in the wild and have been shown to be effective substitutes in previous field and laboratory studies in this population (Kelly, 2006b,2006c,2006d, 2008a). Additionally, the galleries, having previously been used in the field as galleries for weta on many occasions and for long durations, contained chemical cues of both sexes and would be similar to those found in naturally occurring vacant galleries in the area. Individual weta were left in their respective holding arenas for approximately 44-48 hr to allow for exploration and familiarization with the refuge galleries and were observed daily (at $0900 \mathrm{hr}$ ) to insure gallery use prior to data collection.

At $1,600 \mathrm{hr}$, approximately $44 \mathrm{hr}$ post-capture, tree weta and galleries were transferred to individual 7- $L$ transparent plastic arenas (235 mm $\times 120 \mathrm{~mm} \times 355 \mathrm{~mm}$; Sistema Plastics, New Zealand) and placed upright on their short-end, four abreast on four shelves ( $n=16$ arenas) for behavioural observation. To ensure accurate and detailed behavioural measurements, all arenas were video-recorded simultaneously using an infrared digital recording system (SCW 1080P HD Vanguard Series) for two nights between 1,800 and 0900. A large $2 \mathrm{~m}$ window directly opposite and approximately $2 \mathrm{~m}$ away from the experimental holding area provided a natural photoperiod.

\section{1 | Behavioural metrics}

Behavioural attributes analysed from the video recordings included (a) time to first emergence from the gallery, (b) total number of gallery exits (as a measure of activity/vigilance-see below) and (c) total time outside of the gallery. Though these measures incorporate elements of exploration, we characterize them here as estimates of risktaking and vigilance. This is due to the fact that gallery emergence is an inherently risky activity as it increases risk of predation as well as increases risk of losing the gallery to competitors, which may result in an individual being unable to find a suitable refuge before daybreak. In such instances, risk of predation dramatically increases due to the number of diurnal avian insectivores on the island (C.D. 
Kelly, personal observation). Vigilance in this context refers both to watchfulness for potential predators as well as for potential competing males (in terms of optimal gallery protection) as well as females. Latency to first emergence was standardized to account for changes in diurnal photoperiod of individuals over the course of the overall experiment by adjusting the time of first gallery exit to $1 \mathrm{hr}$ before sunset (i.e., minute 0 ) each day. A gallery exit was defined as an individual emerging from an entrance hole with at least $95 \%$ of their total body length exposed. It is important to note that latency to first exit and total number of exits are functionally different in that they represent different elements of this species' daily behavioural repertoire (risky refuge emergence and active vigilance/gallery-checking for mates/competition) and are not auto-correlated. For example, individuals can exit early in the evening and sit motionless while guarding outside of the gallery, or enter and exit the galleries many times over the course of the night or perhaps only within the last hour.

At the completion of the trial $(0900 \mathrm{hr}$, Day 4), weta were manually removed from their galleries and subjected to two assessments of antipredator behaviour. The first assessment involved measuring (a) the intensity and (b) duration of response to the application of light pressure to the thoracic region between an observer's thumb and forefinger (same observer for all trials). Antipredator responses were scored in ascending order of intensity: (a) elevation of a single hind leg, (b) elevation of both hind legs and (c) elevation of hind legs/ mandible flare/spitting. Raising the hind legs is a documented antipredator response of tree weta (Field \& Glasgow, 2001). Duration of response was measured as the time required for the noted antipredator responses to end and normal movement or body positioning to resume (i.e., contact of the tarsus of both hind legs with the substrate). Following this first test, a second antipredator test quantified individual willingness to autotomize (shed or discard) a limb to escape predation threat. This measure involved firmly grasping the femur of the left hind leg with forceps and recording the time to leg autotomy for a maximum of $120 \mathrm{~s}$. However, due to few successful events overall, this behaviour was not included in our analyses.

We euthanized all tree weta via freezing at $-20^{\circ} \mathrm{C}$ following completion of the experimental protocol. We then measured the pronotum length and head length (top of head capsule to tip of right mandible) of every male using digital callipers (Fisher Scientific, Toronto, Ontario, Canada) (see Kelly, 2005a for detailed protocol) and then weighed both males and females to the nearest $0.05 \mathrm{~g}$ (Fisher Scientific SLF103 field balance). We counted the number of ectoparasitic mites (Nothotrombicula deinacridae) following previous studies (Kelly, 2005b; Robb, Forbes, \& Jamieson, 2004). Each female was dissected, and their eggs counted to determine fecundity. Body condition was calculated as the scaled mass index (SMI) (Kelly, 2014; Peig \& Green, 2009, 2010).

\subsection{Statistical analysis}

We estimated sources of variation in behaviour within and among individuals by using a mixed-effect modelling framework (Dingemanse \& Dochtermann, 2013) in which each of three twice-measured focal behaviours (latency to emerge, number of exits and time spent outside gallery) were entered separately in a univariate model (Table 1). We partitioned the total variance into that attributable to individual and residual by including random intercepts for individual identity. We constructed two sets of univariate models: one set investigated the effect of sex (factor: male vs. female) and the other investigated the effect of male morphotype (factor: 8th vs. 9th vs. 10th instar) on mean behavioural expression. All univariate models included the fixed effects test sequence (factor: day 1 vs. day 2), number of ectoparasitic mites (covariate) and scaled mass index (SMI, covariate). We also estimated individual repeatability as the among-individual variance divided by the total variance which is not attributable to fixed effects, thus representing the "adjusted" repeatability (Nakagawa \& Schielzeth, 2010). We similarly analysed response to predation and duration of response but since these behaviours were measured once only (at the end of the trial) we did not include individual ID as a random factor in these models nor could we calculate their repeatability.

Second, we used multivariate models to assess whether the behaviours were part of a behavioural syndrome by quantifying the magnitude and direction of correlations among our five measured behaviours for females and each of the male morphs. Behavioural syndromes represent among-individual correlations (Dingemanse, Dochtermann, \& Nakagawa, 2012) and are ideally investigated by partitioning the unpartitioned (i.e., "raw") phenotypic correlations into their among- and within-individual components (Brommer, 2013; Dingemanse \& Dochtermann, 2013; Dingemanse et al., 2012). Fixed factors were not included in these models. We ran models for 65,000 iterations and thinned them by 50 iterations after a burn-in of 10,000 iterations. Posterior distributions were examined to confirm homogeneity of variances (Gelman \& Hill, 2007).

We also conducted pairwise comparisons of among-individual behavioural variation for all combinations of sex and morph to further explore differences in behavioural syndromes. We accomplished this by calculating "difference matrices" $(D)$, which involves subtracting one matrix (I) from another (i.e., $D_{8 \text { th-9th }}=I_{8 \text { th }}-I_{9 \text { th }}$ ); if I matrices are identical then $D$ will equal zero (see Houslay, Vierbuchen, Grimmer, Young, \& Wilson, 2018). We calculated $95 \%$ confidence intervals for each difference matrix $(D)$.

All statistical analyses were conducted in the R statistical environment with all models run using the MCMCgImm package (Hadfield, 2010). Our univariate mixed effects analyses modelled "latency to emerge" as censored gaussian data (cengaussian), the number of exits and response to predation as Poisson, and time outside and duration of response as gaussian. All non-Poisson behavioural response variables were scaled to standard deviation units (calculated from all observations across both sexes and all male morphs) prior to analysis, which improves effect size comparisons across traits and ameliorates multivariate model fitting in MCMCgImm (described above). We used the mode of the posterior distribution as a point estimate for a given statistic and used the $95 \%$ highest posterior density as a measure of the $95 \%$ credibility interval. Credibility intervals that do not include zero indicate statistical significance. 
ग)
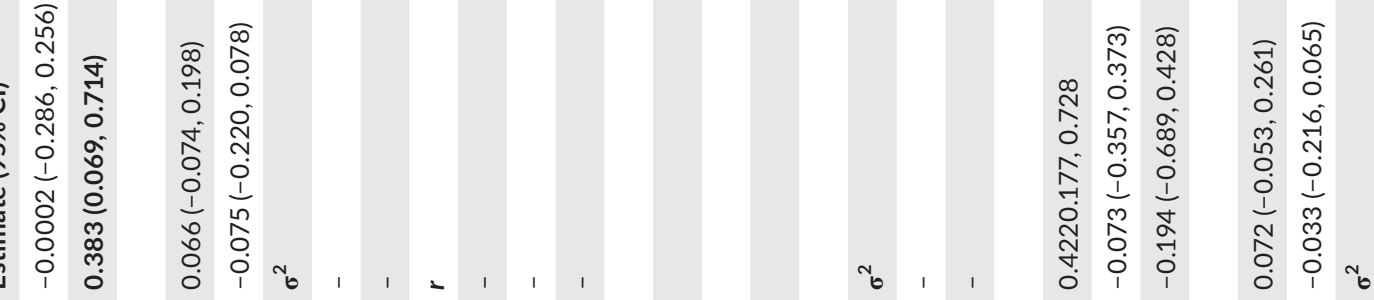

음

गิ

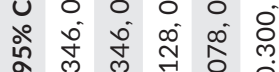




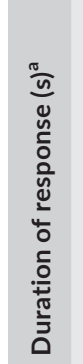

I
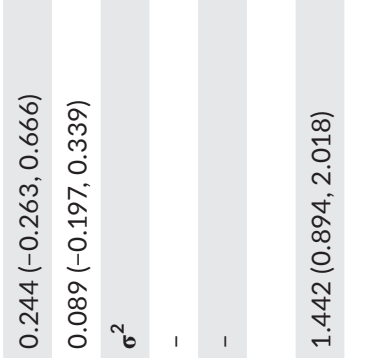

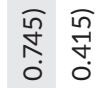

辛

$\begin{array}{lll}1 & 1 \\ 0 & 0 & 0 \\ 1 & 0 & 0\end{array}$

党

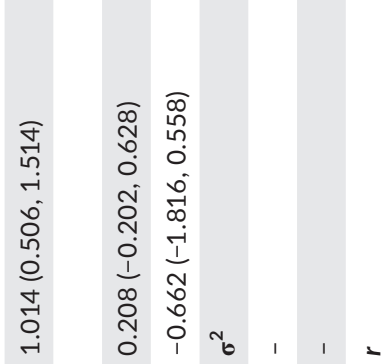

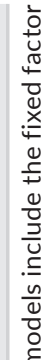

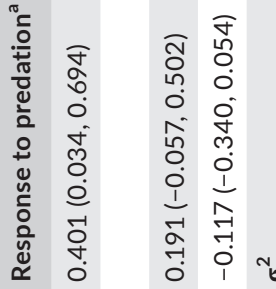

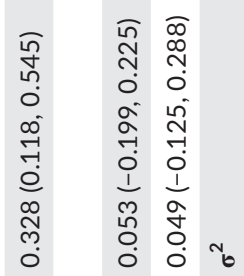

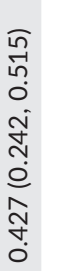

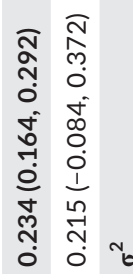

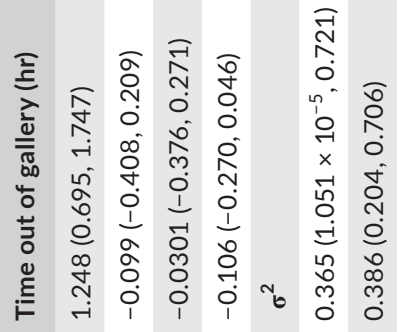

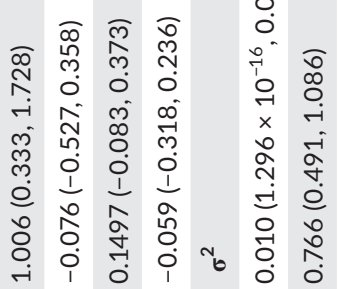

ᄀ

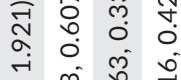

กิ लु

每

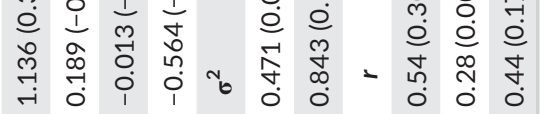

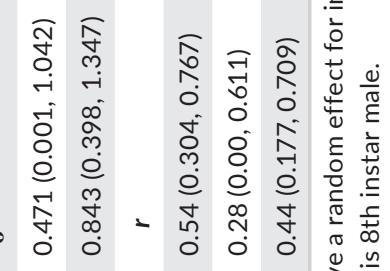

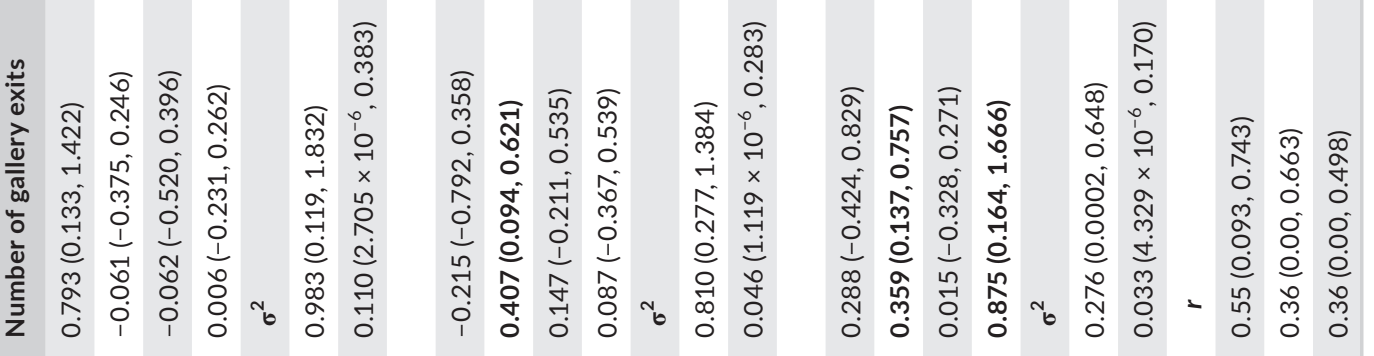

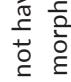

은 훈

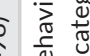

ه

仓 एँ

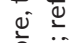

를

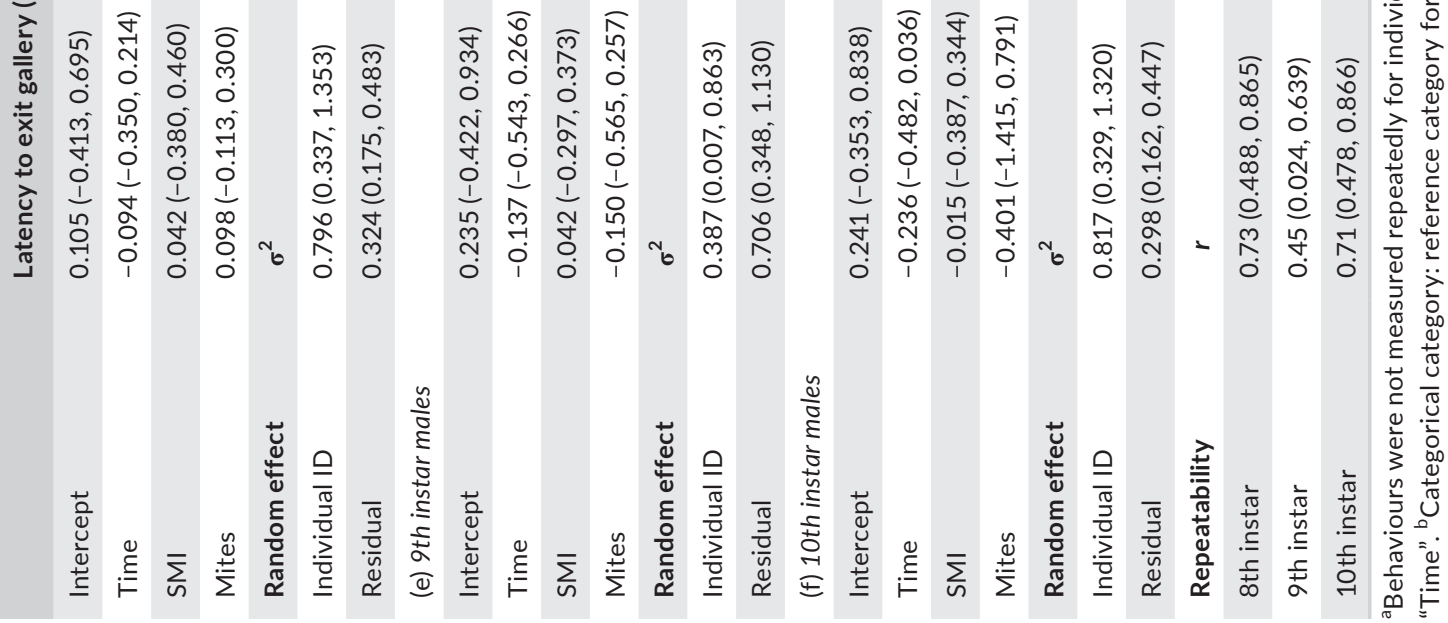




\section{3 | Ethical note}

This research was performed in accordance with the laws guidelines, and ethical standards of the country in which they were performed (New Zealand). All weta were humanely euthanized following behavioural trials to permit morphometric measurements and quantification of reproductive status and parasite load.

\section{3 | RESULTS}

\subsection{Sex and morphotype differences in body condition and parasite load}

Females were in significantly better body condition (scaled mass index) than males (one-way ANOVA with Tukey-transformed SMI: $\mathrm{F} 1,126=17.93, p<0.0001$ ); however, condition did not differ among the three male morphs $(F 2,93=0.96, p=0.39$ ) (Figure 1a). Females had fewer ectoparasitic mites than males (negative binomial GLM: $z=2.57, p<0.001$ ) while smaller males (8th and 9th instar) had higher loads than 10th instar males (8th vs. 10th: $z=-3.86$, $p=0.00012 ;$ 9th vs. 10th: $z=-2.46, p=0.014$ ) (Figure 1b). We therefore included the number of mites and body condition (SMI) as covariates in our exploratory analyses of sources of behavioural variation.

\subsection{Sources of variation in behaviour}

Fixed effects had little overall effect on the expression of behaviour in $\mathrm{H}$.crassidens. We found that the latency to exit the gallery and the number of gallery exits significantly differed between our two sample periods when testing for differences between the sexes (Table 1a), whereas the number of gallery exits differed between sample periods in the males-only analysis (Table 1c). There was a significant effect of sex on intensity of response to a simulated predator attack whereby females exhibited a significantly more intense response to attack than males (Table 1a). Body condition had no significant effect on any of the five measured behaviours (Table 1a). The three behaviours that were measured twice were significantly repeatable across individuals $(r=0.47-0.53$; Table 1a).

None of our fixed effects were significantly related to female behaviour (Table 1b). Male morphs did not significantly differ in their latency to exit the gallery, number of gallery exits (entrances) or duration of antipredator response (Table 1c). However, 10th instar males spent more time outside of the gallery than either 8th instar (Table 1c) or 9th instar (estimate for 9th vs. 10th instar males: 0.70 [95\% Cl, 0.316, 1.1012]) males. Male morphs did not differ in their intensity of response to predator attack or in their duration of response (Table 1c). Neither condition nor ectoparasite load affected male behaviour (Table 1c).

Morph-specific analyses (Table $1 \mathrm{~d}-\mathrm{f}$ ) revealed no significant effect of body condition or ectoparasitic load on behaviour in 8th or 9th instar males. However, 10th instar males with higher mite loads made more gallery exits/entrances and 10th instar males in better condition responded more intensely to simulated predator attack (Table 1f). Examination of residual variation suggests that 8 th instar males exhibit relatively little plasticity in each of the repeatedly measured behavioural traits. Ninth instar males, on the other hand, showed relatively high residual variation in latency to emerge from a gallery and the time spent out of the gallery while 10th instar males displayed high variation only in time spent outside the gallery. All male morphs exhibited significant repeatabilities in all three repeatedly measured behaviours.

\section{3 | Behavioural covariance}

Because all our twice-measured behaviours were significantly repeatable (Table 1 ), they, thus, possessed the potential to harbour significant among-individual variation (see Dingemanse \& Dochtermann, 2013). Two pairs of repeatedly measured behaviours were significantly negatively correlated (i.e., latency-time out, latency-number of exits), and one pair (i.e., number of exitstime out) was significantly positively correlated at the unpartitioned phenotypic level when the sexes were pooled (Table 2a). Latency to exit was negatively correlated with time out of gallery and number of gallery exits, whereas the number of gallery exits was positively correlated with time out of gallery (Table 2a). These raw correlations were driven by both among- and between-individual correlations.

None of our repeatedly measured behaviours were correlated with any of our antipredator behaviours when analysed separately in the three male morphs (Table $2 b-d$ ) or in females (Table 2e). Females and the three morphs were largely concordant at the raw phenotypic level and in agreement with the pooled data: latency to exit was negatively correlated with time out of gallery and number of gallery exits whereas the number of gallery exits was positively correlated with time out of gallery (except in 10th instar males and females). Because 9th instar males are thought to exhibit a jack-ofall-trades mating strategy, we expected them to show a high degree of behavioural variation (i.e., have significant within-individual correlations). We indeed found that each of the three significant raw correlations in 9th instar males were driven primarily by significant residual correlations (Table 2c); males change their levels of behaviour across tests. On the other hand, the three significant raw phenotypic correlations for 8th instar males were driven primarily by significant among-individual correlations (Table 2b); males maintain their levels of behaviour across tests. Tenth instar males and females exhibited the fewest significant correlations at any level (Table 2d).

Female fecundity was not significantly related to any of the five measured behaviours (Table 3).

\subsection{Among-individual behavioural (co)variation between sexes and morphs}

Difference matrices suggest females expressed significantly greater variation in latency to exit the gallery and number of exits than 8th 
TAB LE 2 Estimates ( $\pm 95 \%$ confidence intervals) for unpartitioned phenotypic (i.e., raw), among-individual and within-individual correlations $(r)$ between 5 behavioural traits measured in male $(n=96)$ and female $(n=32)$ Wellington tree weta

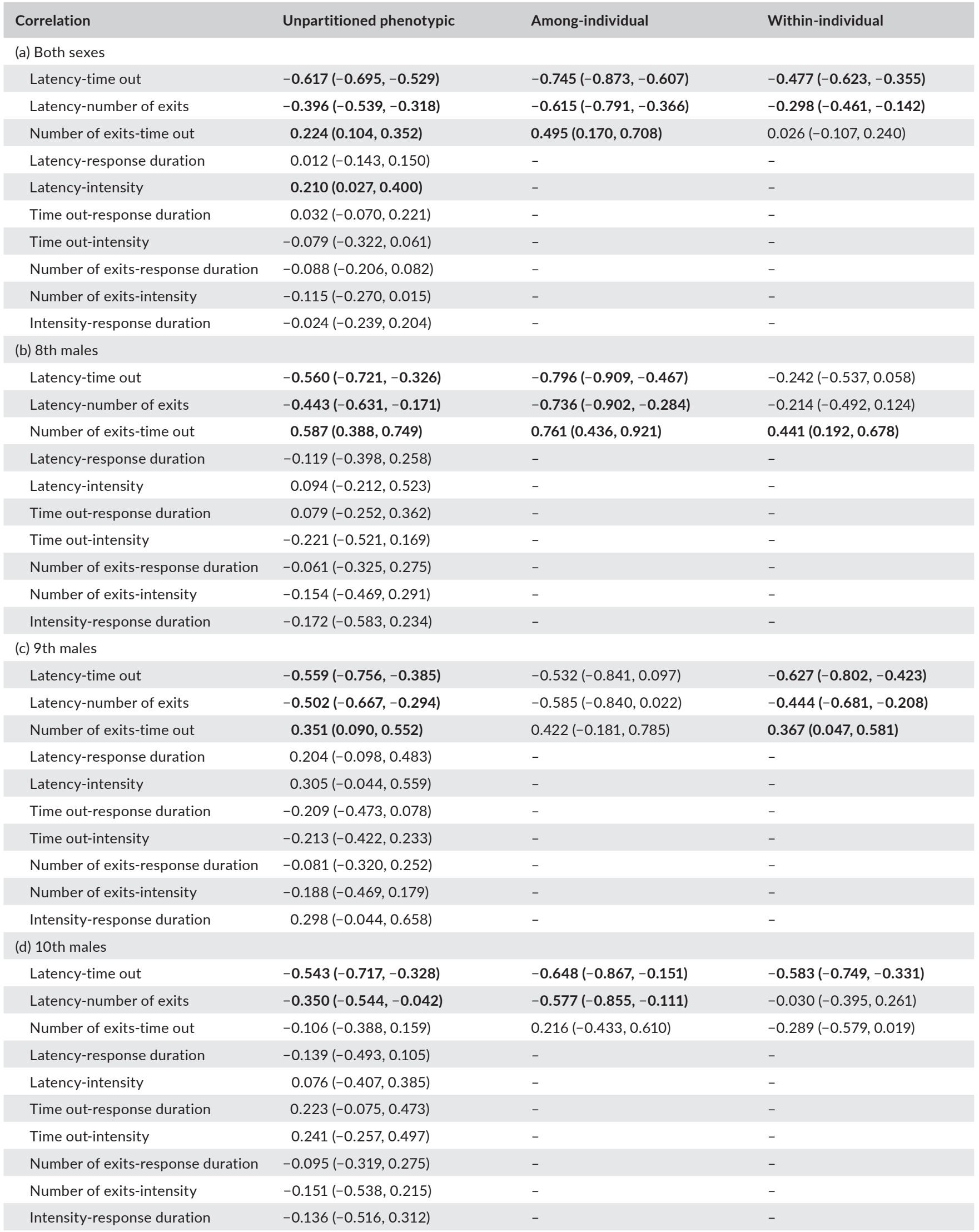


TABLE 2 (Continued)

\begin{tabular}{llll} 
Correlation & Unpartitioned phenotypic & Among-individual & Within-individual \\
\hline (e) Females & & & \\
\hline Latency-time out & $-0.669(-0.775,-0.435)$ & $-0.823(-0.940,-0.467)$ & $-0.489(-0.741,-0.256)$ \\
\hline Latency-number of exits & $-0.444(-0.647,-0.162)$ & $0.236(-0.230,0.649)$ & $-0.624(-0.768,-0.290)$ \\
\hline Number of exits-time out & $0.145(-0.188,0.400)$ & $0.539(-0.156,0.772)$ & $-0.035(-0.405,0.258)$ \\
\hline Latency-response duration & $0.158(-0.224,0.363)$ & - & - \\
\hline Latency-intensity & $0.178(-0.265,0.462)$ & - & - \\
\hline Time out-response duration & $0.063(-0.220,0.401)$ & - & - \\
\hline Time out-intensity & $-0.189(-0.562,0.259)$ & - & - \\
\hline Number of exits-response duration & $0.102(-0.342,0.335)$ & - & - \\
\hline Number of exits-intensity & $-0.268(-0.592,0.078)$ & - & - \\
\hline Intensity-response duration & $-0.274(-0.534,0.234)$ & - & - \\
\hline
\end{tabular}

Note. Among- and within-individual estimates are not given for correlations involving antipredator behaviours because these behaviours were measured once only. Bold values indicate values where $95 \%$ confidence intervals do not overlap zero.

instar males (Table 3a) while exhibiting significantly less variation in time outside the gallery than all male morphs (Table 3a-c). Eighth and 10th instar males exhibited significantly reduced latency-number of exits covariation than females. Females also expressed significantly greater latency-time outside covariation than 9th and 10th instar males (Table 3b,c). Of the three male morphs, females were most similar to 9th instar males in terms of their behavioural (co)variation ( $D$ overlaps zero in three comparisons; Table 3c). Ninth and 10th instar males generally exhibit significantly greater behavioural variation than 8th instar males (Table 3d,e), while also having significantly reduced covariation between latency-time out and latency-number of exits than 8th instar males. The covariation in time out-number of exits was significantly greater in 9th and 10th instar than in 8th instar males (Table 3d,e). Ninth and 10th instar males are more similar to each other in their behavioural (co)variation than they are to 8th instar males ( $D$ overlaps zero in three comparisons; Table $3 f$ ).

\section{4 | DISCUSSION}

Contrary to our predictions, we did not find any consistent behavioural differences between male morphs or between the sexes in Wellington tree weta. However, that 8th instar males appear to exhibit behavioural syndrome structure and that 9th instar males appear to exhibit a jack-of-all-trades strategy lends partial support for our hypothesis.

Our results demonstrate that three ecologically relevant behaviours (latency to exit a gallery, time outside a gallery, number of gallery exits) are significantly repeatable in male and female Wellington tree weta. These three behaviours are significantly correlated at the phenotypic level when the data for both sexes are combined, which suggests that, as predicted, the time spent outside of the gallery was negatively correlated with latency to first gallery exit and positively correlated with total number of exits. Partitioning the raw phenotypic correlations revealed that these correlations were driven by significant correlations at the within- and among-individual levels. We also found that individuals making with longer latency to exit a gallery exhibited a more intense response to a simulated predator attack.

We found no significant sex differences in any of our three gallery-related behaviours. Across the experimental nights, all three behaviours involved with gallery use represented by latency to exit the gallery, total time spent outside of the gallery and total number of exits were highly repeatable and support our initial predictions regarding these traits as suitable measures of boldness behavioural "types" in tree weta (Kelly, 2006a,2006c; Spencer, 1995). Repeatability values (pooled data: 0.47-0.53) were also higher than the average repeatability value of 0.37 for behavioural traits calculated by Bell, Hankison, and Laskowski (2009).

Contrary to our initial prediction, male morphs did not show consistent differences across all behaviours. We did find, however, that 10th instar males spent more time outside the gallery than the other morphs. Our observations during data collection showed that 10 th instar males were largely stationary above the gallery or near the gallery entrance when outside. This suggests that 10th instar males might sit-and-wait for females to enter the gallery to ensure that they (the male) enter last. This is in line with field observations that males are nearly always found near the cavity entrance inside the gallery (C.D. Kelly, personal observation). The observed behaviour of 10th instar males might also ensure that they have a better opportunity to defend the gallery against rival males or avoid injury associated with fighting a rival with greater RHP (Kelly, 2006a,2006d).

Comparison of male morph behaviour reveals that the raw phenotypic correlations between behaviours in 8th instar males are driven by among-male variation. Eighth instar males also exhibited the lowest residual variation for repeatedly measured behaviour and the greatest repeatability for each behaviour. These findings support the hypothesis that 8th instar males have behavioural syndrome structure. On the other hand, raw phenotypic correlations for 9th instar males appear to be driven by within-male variation. This 
TAB LE 3 Difference $(D)$ variance-covariance matrices for comparisons of among-individual behavioural variation between females and male morphs

\begin{tabular}{|c|c|c|c|}
\hline & Latency & Time out & Number of exits \\
\hline \multicolumn{4}{|c|}{ (a) 8th instar males versus females } \\
\hline Latency & $0.253(0.169,0.337)$ & & \\
\hline No. exits & $-0.353(-0.437,-0.269)$ & $0.344(0.260,0.427)$ & $0.366(0.283,0.450)$ \\
\hline \multicolumn{4}{|c|}{ (b) 9th instar males versus females } \\
\hline Time out & $0.272(0.189,0.356)$ & $-0.415(-0.499,-0.332)$ & \\
\hline No. exits & $-0.083(-0.167,0.001)$ & $0.002(-0.081,0.086)$ & $-0.111(-0.195,-0.027)$ \\
\hline \multicolumn{4}{|c|}{ (c) 10 th instar males versus females } \\
\hline Latency & $0.068(-0.016,0.151)$ & & \\
\hline Time out & $0.149(0.065,0.232)$ & $-0.153(-0.236,-0.069)$ & \\
\hline \multicolumn{4}{|c|}{ (d) 8th versus 9th instar males } \\
\hline Latency & $0.175(0.091,0.258)$ & & \\
\hline Time out & $-0.256(-0.340,-0.173)$ & $0.176(0.093,0.260)$ & \\
\hline No. exits & $-0.270(-0.354,-0.186)$ & $0.341(0.258,0.425)$ & $0.478(0.394,0.561)$ \\
\hline \multicolumn{4}{|c|}{ (e) 8 th versus 10 th instar males } \\
\hline Latency & $0.185(0.102,0.269)$ & & \\
\hline Time out & $-0.133(-0.216,-0.049)$ & $-0.086(-0.170,-0.003)$ & \\
\hline No. exits & $-0.252(-0.336,-0.169)$ & $0.428(0.345,0.512)$ & $0.430(0.347,0.514)$ \\
\hline \multicolumn{4}{|c|}{ (f) 9 th versus 10 th instar males } \\
\hline Latency & $0.010(-0.073,0.094)$ & & \\
\hline
\end{tabular}

Note. Differences $( \pm 95 \% \mathrm{Cl})$ in behavioural variances appear on the diagonals, and differences in behavioural covariances on the off-diagonal. Bold values indicate values where $95 \%$ confidence intervals do not overlap zero.

finding suggests that changes in exit/entry behaviour (i.e., latency to exit and number of exits) were matched by changes in the duration of time spent outside. These males also exhibited high residual variation in latency to exit the gallery and the time spent outside the gallery (i.e., are more behaviourally plastic) and the lowest repeatability for each behaviour. However, it is not possible at this time to conclude whether the repeatabilities for 9 th instar males are simply due to behavioural differences (assuming equal plasticity) or reflect genuinely greater plasticity (with similar degrees of individual variation). Taken together, our results lend support to the hypothesis that 9th instar males represent a jack-of-all-trades strategy whereby they can fight for access to groups of adult females or sneak/search for mates. Tenth instar males showed intermediate levels of residual behavioural variation and repeatability, and expressed the fewest significant correlations between behaviours. Difference matrices suggest that 9 th and 10 th instar males were similar to each other in their covariation between latency-number of exits as well as in their variation in latency and number of exits.

The 8th and 9th instar males are the only morphs to exhibit significant raw phenotypic correlations for each pair of repeatedly measured behaviours; 10th instar expressed significant covariation between latency-time out and latency-number of exits only (similar to females). Examination of difference matrices suggests that 8th instar males differ from 9th and 10th instar males in behavioural (co) variation, whereas (no differences overlap zero) 9th and 10th instar are more similar (three of six differences overlap zero).

Our assays showed a significant female bias in the intensity of response to predation threat (i.e., degree of leg-raise). This sex difference in antipredator behaviour might reflect inter-sexual differences in antipredator strategies, with males using their enlarged mandibles for defence in combination with or in place of leg raises, which represents the females' primary defence mechanism. Surprisingly, body condition affected antipredator behaviour in 10th instar males only as males in better condition reacted more intensely to attack. There is no obvious reason as to why this behaviour should be conditiondependent in only one morph. We found no sex difference, or differences among morphs, in the time required to resume normal posture and behaviour after a predator attack.

We hypothesized that females would exhibit the naturally selected behavioural optimum and any deviance from this by males 
could be attributed to sexual selection on males (Lande, 1980). Contrary to our hypothesis females did not generally differ from males in their behaviour. The only consistent difference that we detected between females and the different male morphs was that females exhibited significantly reduced variation in the time spent outside the gallery (Table 3). The raw phenotypic correlations in females and 10th instar males appear to be driven by a mix of among- and within-individual variation and 9th instar males and females exhibit similar levels of residual variation in the latency to exit a gallery. Examination of difference matrices suggests that females are most similar to 9th instar males (most differences overlap zero) and most different from 8th instar males (fewest differences overlap zero).

In terms of Wellington tree weta behavioural ecology, we cannot say what the purpose or fitness-relevance of these correlated behaviours is or whether the purpose is the same for each sex or morph. For example, females might exit the gallery earlier in order to search for food, whereas males might search for mates, and females that spend longer outside the gallery might be avoiding sexual harassment by males, whereas males might be ensuring that rival males do not enter their gallery. Given the paucity of current research on strategy-related behavioural syndromes, the current study work represents an important first step in terms of identifying individualand phenotypic-level differences in behaviour for the evolution of alternative mating systems. Future research on the ultimate mechanisms underlying these behaviours and the role of context (in terms of competition and conspecific density) will be necessary to contextualize these results, and their importance in terms of the ecology and evolution of alternative mating strategies in weta.

\section{ACKNOWLEDGEMENTS}

We gratefully acknowledge Frank Higgott and Susan Caldwell of the Department of Conservation (New Zealand) for providing research support, and Niels Dingemanse and Tom Houslay for statistical advice. We also thank Tina Wey for her assistance in the field. This research was performed in accordance with the laws guidelines, and ethical standards of the country in which they were performed (New Zealand).

\section{ORCID}

Alexander D. M. Wilson (iD https://orcid.org/0000-0002-7696-1671 Clint D. Kelly iD https://orcid.org/0000-0002-0693-7211

\section{REFERENCES}

Bell, A. M., Hankison, S. J., \& Laskowski, K. L. (2009). The repeatability of behaviour: A meta-analysis. Animal behaviour, 77, 771-783. https:// doi.org/10.1016/j.anbehav.2008.12.022

Binder, T. R., Wilson, A. D. M., Wilson, S. M., Suski, C. D., Godin, J.-G. J., \& Cooke, S. J. (2016). Is there a pace-of-life syndrome linking boldness and metabolic capacity for locomotion in bluegill sunfish? Animal Behaviour, 121, 175-183. https://doi.org/10.1016/j. anbehav.2016.09.006

Bókony, V., Kulcsár, A., Tóth, Z., \& Liker, A. (2012). Personality traits and behavioral syndromes in differently urbanized populations of House Sparrows (Passer domesticus). PLoS ONE, 7, e36639. https:// doi.org/10.1371/journal.pone.0036639

Brockmann, H. J. (2008). Alternative reproductive tactics in insects. In R. F. Oliveira, M. Taborsky, \& H. J. Brockmann (Eds.), Alternative reproductive tactics: An integrative approach (pp. 177-223). Cambridge, UK: Cambridge University Press. https://doi.org/10.1017/ CBO9780511542602

Brockmann, H. J., Oliveira, R. F., \& Taborsky, M. (2008). Integrating mechanisms and function: Prospects for future research. In R. F. Oliveira, M. Taborsky, \& H. J. Brockmann (Eds.), Alternative reproductive tactics: An integrative approach (pp. 471-489). Cambridge, UK: Cambridge University Press. https://doi.org/10.1017/ CBO9780511542602

Brommer, J. E. (2013). On between-individual and residual (co)variances in the study of animal personality: Are you willing to take the "individual gambit"? Behavioral Ecology and Sociobiology, 67, 1027-1032. https://doi.org/10.1007/s00265-013-1527-4

Carter, A. J., Goldizen, A. W., \& Tromp, S. A. (2010). Agamas exhibit behavioral syndromes: Bolder males bask and feed more but may suffer higher predation. Behavioral Ecology, 21, 655-661. https://doi. org/10.1093/beheco/arq036

Chapman, B. B., Hegg, A., \& Ljungberg, P. (2013). Sex and the syndrome: Individual and population consistency in behaviour in rock pool prawn Palaemon elegans. PLoS ONE, 8, e59437. https://doi. org/10.1371/journal.pone.0059437

Dingemanse, N. J., \& Dochtermann, N. A. (2013). Quantifying individual variation in behaviour: Mixed-effect modelling approaches. Journal of Animal Ecology, 82,39-54. https://doi.org/10.1111/1365-2656.12013

Dingemanse, N. J., Dochtermann, N. A., \& Nakagawa, S. (2012). Defining behavioural syndromes and the role of 'syndrome deviation' in understanding their evolution. Behavioral Ecology and Sociobiology, 66, 1543-1548. https://doi.org/10.1007/s00265-012-1416-2

Dingemanse, N. J., Wright, J., Kazem, A. J. N., Thomas, D. K., Hickling, R., \& Dawnay, N. (2007). Behavioural syndromes differ predictably between 12 populations of three-spined stickleback. Journal of Animal Ecology, 76, 1128-1138. https://doi. org/10.1111/j.1365-2656.2007.01284.x

Field, L. H., \& Glasgow, S. (2001). Defence behaviour. In L. H. Field (Ed.), The biology of Wetas, king crickets and their allies (pp. 297-316). Wallingford, UK: CABI Publishing. https://doi. org/10.1079/9780851994086.0000

Gelman, A., \& Hill, J. (2007). Data analysis using regression and multilevel/ hierarchical models. New York, NY: Cambridge University Press.

Gibbs, G. W. (1998). New Zeland weta. Auckland, New Zealand: Reed Books.

Gibbs, G. W. (2001). Habitats and biogeography of New Zealand's Deinacridine and tusked weta species. In L. H. Field (Ed.), The biology of Wetas, king crickets and their allies (pp. 35-55). Wallingford, UK: CABI Publishing. https://doi.org/10.1079/9780851994086.0000

Gross, M. R. (1982). Sneakers, satellites and parentals: Polymorphic mating strategies in North American Sunfishes. Zeitschrift für Tierpsychologie, 60, 1-26. https://doi.org/10.1111/j.1439-0310.1982. tb01073.x

Hadfield, J. D. (2010). MCMC methods for multi-response generalized linear mixed models: The MCMCgImm R Package. Journal of Statistical Software, 33, 22.

Hanlon, R. T., Naud, M.-J., Shaw, P. W., \& Havenhand, J. N. (2005). Transient sexual mimicry leads to fertilization. Nature, 433, 212. https://doi.org/10.1038/433212a

Houslay, T. M., Vierbuchen, M., Grimmer, A. J., Young, A. J., \& Wilson, A. J. (2018). Testing the stability of behavioural coping style across stress 
contexts in the Trinidadian Guppy. Functional Ecology, 32(2018), 424438. https://doi.org/10.1111/1365-2435.12981

Kelly, C. D. (2005a). Allometry and sexual selection of male weaponry in Wellington tree weta, Hemideina crassidens. Behavioral Ecology, 16, 145-152. https://doi.org/10.1093/beheco/arh141

Kelly, C. D. (2005b). Sexual selection and infection by ectoparasites in Wellington tree weta, Hemideina crassidens (Orthoptera: Anostostomatidae). Austral Ecology, 30, 648-654. https://doi. org/10.1111/j.1442-9993.2005.01506.x

Kelly, C. D. (2006a). Fighting for harems: Assessment strategies during male-male contests in the sexually dimorphic Wellington tree weta. Animal Behaviour, 72, 727-736. https://doi.org/10.1016/j. anbehav.2006.02.007

Kelly, C. D. (2006b). Movement patterns and gallery use by the sexually dimorphic Wellington tree weta. New Zealand Journal of Ecology, 30, 273-278.

Kelly, C. D. (2006c). The relationship between resource control, association with females and male weapon size in a male dominance insect. Ethology, 112, 362-369. https://doi.org/10.1111/j.1439-0310.2006.01193.x

Kelly, C. D. (2006d). Resource quality or harem size: What influences male tenure at refuge sites in tree weta (Orthoptera : Anostostomatidae)? Behavioral Ecology and Sociobiology, 60, 175-183. https://doi. org/10.1007/s00265-005-0154-0

Kelly, C. D. (2008a). Identifying a causal agent of sexual selection on weaponry in an insect. Behavioral Ecology, 19, 184-192. https://doi. org/10.1093/beheco/arm121

Kelly, C. D. (2008b). Why do male tree weta aggressively evict females from galleries after mating? Ethology, 114, 203-208. https://doi. org/10.1111/j.1439-0310.2007.01451.x

Kelly, C. D. (2014). Effect of an immune challenge on the functional performance of male weaponry. Behavioural Processes, 108, 197-203. https://doi.org/10.1016/j.beproc.2014.11.001

Kelly, C. D., \& Adams, D. C. (2010). Sexual selection, ontogenetic acceleration, and hypermorphosis generates male trimorphism in Wellington Tree Weta. Evolutionary Biology, 37, 200-209. https://doi. org/10.1007/s11692-010-9096-1

Kodric-Brown, A. (1986). Satellites and sneakers: Opportunistic male breeding tactics in pupfish (Cyprinodon pecosensis). Behavioral Ecology and Sociobiology, 19, 425-432. https://doi.org/10.1007/BF00300545

Küpper, C., Stocks, M., Risse, J. E., dos Remedios, N., Farrell, L. L., McRae, S. B., ... Burke, T. (2016). A supergene determines highly divergent male reproductive morphs in the ruff. Nature genetics, 48, 79-83. https://doi.org/10.1038/ng.3443

Lande, R. (1980). Sexual dimorphism, sexual selection, and adaptation in polygenic characters. Evolution, 34, 292-305. https://doi. org/10.1111/j.1558-5646.1980.tb04817.x

Michelangeli, M., Chapple, D. G., \& Wong, B. B. M. (2016). Are behavioural syndromes sex specific? Personality in a widespread lizard species. Behavioral Ecology and Sociobiology, 70, 1911-1919. https:// doi.org/10.1007/s00265-016-2197-9

Nakagawa, S., \& Schielzeth, H. (2010). Repeatability for Gaussian and non-Gaussian data: A practical guide for biologists. Biological Reviews, 85, 935-956.

Oliveira, R. F., Taborsky, M., \& Brockmann, H. J. (2008). Alternative reproductive tactics: An integrative approach. Cambridge, UK: Cambridge University Press. https://doi.org/10.1017/CBO9780511542602

Peig, J., \& Green, A. J. (2009). New perspectives for estimating body condition from mass/length data: The scaled mass index as an alternative method. Oikos, 118, 1883-1891. https://doi. org/10.1111/j.1600-0706.2009.17643.x
Peig, J., \& Green, A. J. (2010). The paradigm of body condition: A critical reappraisal of current methods based on mass and length. Functional Ecology, 24, 1323-1332. https://doi. org/10.1111/j.1365-2435.2010.01751.x

Réale, D., Reader, S. M., Sol, D., McDougall, P. T., \& Dingemanse, N. J. (2007). Integrating animal temperament within ecology and evolution. Biological Reviews, 82, 291-318. https://doi. org/10.1111/j.1469-185X.2007.00010.x

Robb, T., Forbes, M. R., \& Jamieson, I. G. (2004). Engorgement success of parasitic mites on adult sexes of the colour polymorphic mountain stone weta. New Zealand Journal of Zoology, 31, 249-254. https://doi. org/10.1080/03014223.2004.9518377

Schuett, W., Tregenza, T., \& Dall, S. R. X. (2010). Sexual selection and animal personality. Biological Reviews, 85, 217-246. https://doi. org/10.1111/j.1469-185X.2009.00101.x

Shuster, S. M. (2008). The expression of crustacean mating strategies. In R. F. Oliveira, M. Taborsky, \& H. J. Brockmann (Eds.), Alternative reproductive tactics: An integrative approach (pp. 224-250). Cambridge, UK: Cambridge University Press.

Shuster, S. M., \& Wade, M. J. (2003). Mating systems and strategies. Princeton, NJ: Princeton University Press.

Sih, A., Bell, A. M., Johnson, J. C., \& Ziemba, R. E. (2004). Behavioral syndromes: An integrative overview. Quarterly Review of Biology, 79, 241-277. https://doi.org/10.1086/422893

Spencer, A. (1995). Sexual maturity in the male tree weta Hemideina crassidens (Orthoptera: Stenopelamatidae). Wellington, New Zealand: Victoria University of Wellington.

Taborsky, M., \& Brockmann, H. J. (2010). Alternative reproductive tactics and life history phenotypes. In P. Kappeler (Ed.), Animal behaviour: Evolution and mechanisms (pp. 537-586). Berlin, Heidelberg: Springer Berlin Heidelberg. https://doi. org/10.1007/978-3-642-02624-9

Taborsky, M., Oliveira, R. F., \& Brockmann, H. J. (2008). The evolution of alternative reproductive tactics: Concepts and questions. In R. F. Oliveira, M. Taborsky, \& H. J. Brockmann (Eds.), Alternative reproductive tactics: An integrative approach (pp. 1-22). Cambridge, UK: Cambridge University Press.

Wilson, A. D. M., \& Krause, J. (2012). Personality and metamorphosis: Is behavioral variation consistent across ontogenetic niche shifts? Behavioral Ecology, 23, 1316-1323. https://doi.org/10.1093/beheco/ $\operatorname{ars} 123$

Wilson, A. D. M., Szekeres, P., Violich, M., Gutowsky, L. F. G., Eliason, E. J., \& Cooke, S. J. (2017). Activity syndromes and metabolism in giant deep-sea isopods. Deep Sea Research Part I: Oceanographic Research Papers, 121, 237-244. https://doi.org/10.1016/j. dsr.2017.02.003

Wilson, A. D. M., Whattam, E. M., Bennett, R., Visanuvimol, L., Lauzon, C., \& Bertram, S. M. (2010). Behavioral correlations across activity, mating, exploration, aggression, and antipredator contexts in the European house cricket, Acheta domesticus. Behavioral Ecology and Sociobiology, 64, 703-715. https://doi.org/10.1007/ s00265-009-0888-1

How to cite this article: Wilson ADM, Kelly CD. Do alternative reproductive strategies in the Wellington tree weta represent different behavioural types? Ethology. 2019;125:380-391. https://doi.org/10.1111/eth.12862 